\title{
Ética en Trabajo Social: una propuesta de indicadores
}

\author{
Ethics in Social Work: a set of indicators \\ Paulina Morales Aguilera \\ Comisión Nacional de Investigación Científica y Tecnológica, Universidad Católica Silva Henríquez, Chile \\ correopaulinama@gmail.com
}

Recibido: 30/10/2013

Revisado: 09/01/2014

Aceptado: 16/02/2015

Disponible on line: $10 / 06 / 2015$

\begin{abstract}
Resumen
La ética es una dimensión inherente al Trabajo Social desde sus inicios, y lo sigue siendo en la actualidad, especialmente ante las patentes desigualdades e injusticias que se constatan, y frente a las cuales la respuesta profesional debe ser capaz de articular los diversos elementos de su intervención, con un saber y un hacer marcados por la excelencia y por la necesidad de revisión permanente. En tal sentido, el presente artículo reflexiona sobre la dimensión ética en Trabajo Social, fundamentalmente en términos de las posibilidades que ofrece para evaluar su desempeño éticamente. Para ello, se recurre a la propuesta de «indicadores éticos» del filósofo español Juan Carlos Siurana, a partir de cuyos contenidos se desprenden elementos sustantivos para una configuración de indicadores propios del Trabajo Social. Sus ideas-fuerza, especificidades y su riqueza se engloban en un conjunto de reflexiones que acompañan al esquema de indicadores al que se hace referencia.
\end{abstract}

Palabras clave: ética, Trabajo Social, evaluación, indicadores, excelencia.

\begin{abstract}
Ethics is an inherent dimension to social work from the beginning, and remains so today, especially given the glaring inequalities and injustices that are detected today. A professional answer must be able to articulate diverse elements of its practice, with a need for ongoing review of both, knowledge and act marked by excellence. As such, this article reflects the ethical dimension in Social Work, mainly in terms of the possibilities to assess their ethical performance. To this end, we resort to the proposed «ethical indicators «of Spanish philosopher Juan Carlos Siurana, from which substantive elements can be released for an own configuration of social work indicators. Key ideas, specificities and essences of these indicators are included in a set of reflections that accompany the system of indicators to which reference is made.
\end{abstract}

Keywords: ethics, Social Work, evaluation, indicators, excellence.

Referencia normalizada: Morales Aguilera, P. (2015): «Ética en Trabajo Social: una propuesta de indicadores». Cuadernos de Trabajo Social, 28(1): 39-48.

Sumario: 1. Cuestiones preliminares. 2. La perspectiva de los indicadores éticos. 3. La perspectiva de los trabajadores sociales. 4. La perspectiva de los ciudadanos. 5. Principales ideas-fuerza del esquema de indicadores éticos para Trabajo Social. 6. Referencias bibliográficas.

\section{Cuestiones preliminares}

Ciertamente, la reflexión ética en Trabajo Social siempre es necesaria y nutritiva. El quehacer cotidiano hace emerger múltiples interrogantes y dilemas que requieren una búsqueda permanente y actualizada de referentes éticos para responder a ellos adecuadamente. Como se reconoce, valores como la justicia, la igualdad o la dignidad humana han estado y están en la base de la configuración ética de la profesión. Para algu- nos autores - consideración a la que se suman estas líneas - son en definitiva los derechos humanos el sustento ético del Trabajo Social en la actualidad. No obstante, esta adscripción al prisma de derechos no significa una opción aproblemática, en buena medida por la distancia que naturalmente existe entre las teorías o perspectivas ético-filosóficas existentes y los contextos concretos en los cuales los trabajadores sociales deben tomar decisiones. 
Cierto es que se reconoce un impulso ético latente, un llamado a actuar conforme a valores socialmente reconocidos, como los mencionados, empero ello no siempre resulta esclarecido debido a la multiplicidad de factores intervinientes al intentar conciliar, en lo cotidiano, los planos teleológico, deontológico y pragmático. Si bien es cierto que este esquema en tres niveles (Bermejo, 1996) ha contribuido altamente a la reflexión ética en Trabajo Social, se reconocen sus limitaciones especialmente en términos de las dificultades para ligar la dimensión teleológica con la pragmática, pese a los aportes de la dimensión deontológica intermedia. Junto con esto, una de las grandes críticas que es posible realizar a esta propuesta dice relación con cierta unilateralidad en términos de que se centra en la mirada de los propios trabajadores sociales sin integrar la visión -al menos más influyente y directamente- de los sujetos participantes en los procesos de intervención, en tanto prisma relevante en el momento de reflexionar éticamente sobre el desempeño profesional.

En el camino hacia nuevas reflexiones y propuestas sobre Ética y (en) Trabajo Social, capaces de contribuir en parte a superar dificultades como las aludidas, emerge esta propuesta de desarrollar «indicadores» para evaluar éticamente su ejercicio. Esta iniciativa encuentra sus orígenes en los planteamientos del filósofo Juan Carlos Siurana ${ }^{1}$, quien en su obra, La sociedad ética, delinea un conjunto de indicadores para «evaluar éticamente a una sociedad», como bien añade en el subtítulo, desde el campo de lo que actualmente se denomina éticas aplicadas. Este autor parte incorporando la dimensión cotidiana de la reflexión ética, reconociendo que ella no es tarea privativa de los filósofos, sino que debe ser asumida por quienes desarrollan una actividad profesional cuyas consecuencias, positivas o negativas, afectan a toda la sociedad.

En las líneas que siguen, entonces, se presentará de manera acotada la propuesta de Siurana para exponer, en un segundo momento, una propuesta propia de indicadores éticos para Trabajo Social. Tras ello se incluyen, a modo de cierre, un conjunto de reflexiones en torno a tales indicadores ${ }^{2}$.

Finalmente, cabe precisar que este ejercicio de elaboración de indicadores está, ¡cómo no!, íntimamente ligado e imbuido de su pertenencia al contexto espacial y conceptual del Trabajo Social latinoamericano en general y del chileno en particular. Se espera, no obstante, que sea una contribución a un nutritivo diálogo ético intercontinental, en cuyo marco se podrán advertir no pocos puntos de encuentro que se estima otorgan significado y validez a los contenidos del presente artículo. Ello, dado que:

El trabajo social tiene una base común que le da sentido en cualquier país donde se desarrolla, pero recibe una gran influencia de la cultura del propio contexto social donde pertenece, ya que su expresión y evolución están influidas por las formas de vida y de relación social propias de cada lugar y de la política social imperante en cada momento histórico (Rosell, 2000, p. 100).

\section{La perspectiva de los indicadores éticos}

\subsection{Aspectos generales}

Las pistas iniciales del esquema propuesto por Siurana remiten a ciertas condiciones para dar respuesta a los dilemas y (o) decisiones éticas cotidianas; tales condiciones son las de racionalidad y validez; esto es, que deben ser fruto de un ejercicio activo de la razón y que deben ser legítimas, a fin de poder tener una convicción interna sólida y fundada de ellas. Junto con esto, se trata de un ejercicio de la razón que se despliega de manera dialógica en un espacio público en donde sólo deberá primar la fuerza de los argumentos. Esta idea se desprende de la pertenencia de Siurana a la tradición discursiva que fundaran, a inicios de los años setenta, Karl-Otto Apel y Jürgen Habermas.

Asimismo, se releva el papel del impulso ético subyacente al actuar, cuestión que ciertamente ha sido parte constitutiva de la profesión desde sus orígenes, en tanto fruto de un rechazo cabal frente a situaciones de miseria humana, no sólo en sentido material, sino también en térmi-

\footnotetext{
${ }^{1}$ Académico de la Universidad de Valencia, España. Doctor en Filosofía.

${ }^{2}$ Cabe señalar que, para el proceso de elaboración de los indicadores éticos para Trabajo Social, se ha contado con la orientación del profesor Siurana, a fin de cautelar la coherencia con las directrices de su propuesta original.
} 
nos de menosprecio social o denegación de reconocimiento de la propia identidad. Por ello, Siurana identifica como destinatarios de la reflexión ética a quienes comparten la idea de que es posible configurar de otra manera la realidad que nos rodea, postura claramente opuesta al determinismo fundamentado en la naturaleza o al inmovilismo amparado en la tradición. Por el contrario, sus esfuerzos van destinados a,

Las personas que se conmueven ante la pobreza y la falta de libertades, que desean conocer cuál es el camino a seguir para llegar a una situación de mayor justicia, y que quieren colaborar en esa tarea. A este tipo de seres humanos yo les llamo los «buscadores» (Siurana, 2009, p. 14).

Los trabajadores sociales son, sin duda, buscadores, pero habría que agregar algo más: deben ser «buscadores profesionales». Esto significa que no basta con el impulso ético inicial, sino que es necesario bregar cada día por una mayor profesionalización del quehacer con una mirada crítica, abierta al diálogo y orientada a la excelencia.

Ahora bien, ¿por qué construir indicadores éticos para Trabajo Social? En primer lugar, debido a que la propuesta de Siurana no contempla marcadores específicos para esta disciplina. En segundo término, este esfuerzo se fundamenta en un punto específico de discrepancia con los planteamientos del autor, quien, pese a no desarrollar indicadores específicos para Trabajo Social, plantea sí su consideración genérica acerca de la pertenencia de éste al conjunto de las denominadas profesiones sanitarias, entre las cuales menciona: medicina, enfermería y farmacia, entre otras. Cierto es que la impronta sanitaria fue parte inherente de la profesión en sus orígenes. En el caso de Chile, específicamente, no es casual que la primera Escuela de Servicio Social, nacida en $1925^{3}$, lo hiciera al amparo de la Junta de Beneficencia de Santiago, que se ocupaba de la administración de los hospitales. Más aún, la malla curricular de esta primera Escuela daba cuenta de dicho énfasis, al incorporar asignaturas tales como Puericultura, Higiene y Deontología, Atención de Enfermos, Dietética Generales, entre otras (Morales, 2010). No obstante, actualmente es posible realizar una lectura crítica de dicha asociación, no en relación con el pasado que supuso la profesionalización de un quehacer antes sólo ligado a la caridad y a la filantropía, sino respecto de la imposibilidad de seguir manteniendo dicha asociación en el contexto actual, especialmente en los ámbitos latinoamericano en general y chileno en particular ${ }^{4}$.

\subsection{Construcción de indicadores éticos}

Desde una óptica claramente normativa, Siurana comienza el acercamiento al terreno de los indicadores éticos enfatizando el ámbito de las personas individuales, en virtud de lo que denomina una «brújula para la vida moral». Esta especie de carta de navegación se desglosa en tres niveles compuestos de dos rasgos inherentes a cada uno de ellos, tal y como se muestra en el siguiente esquema (Siurana, 2009, p. 326):

$$
\text { Niveles Rasgos }
$$

(1) Autocomprensión 1) Sentido

2) Intersubjetividad

(2) Fundamentación

1) Reflexión

2) Criterio

(3) Aplicación
1) Moral postconven- cional

2) Corresponsabilidad

Los niveles mencionados remiten a las denominadas tres tareas de la ética, que en este caso se han llevado al plano individual a fin de servir de orientación de las personas en sus tareas de

${ }^{3}$ Que es también la primera Escuela de Servicio Social de América Latina.

4 Fundamentalmente, las críticas hacia dicha pertenencia apuntan en las siguientes direcciones: 1) El cariz sanitario en los orígenes de la profesión estaba fuertemente ligado a la noción de higienización y de moralización; un ejercicio profesional abocado a una limpieza social respecto a una población carente de educación, de recursos y de buenos hábitos de aseo. 2) La noción de intervención tiene resabios de lo que ocurre en profesiones como medicina o enfermería, en las cuales la intervención se despliega sobre sujetos/pacientes anestesiados, inactivos, imposibilitados para participar en el proceso, cuestión contraria al énfasis participativo y ciudadano del Trabajo Social en la actualidad. 3) La inclusión del Trabajo Social en el concierto de las profesiones sanitarias resulta hoy insostenible, dada la diversidad de espacios profesionales nuevos y distintos que ha ido ocupando la profesión, ya no sólo al amparo del Estado, sino también en la sociedad civil. 
autocomprensión, argumentación y aplicación. En este sentido, se releva la importancia de esta lectura atendiendo a las personas, entendidas como sujetos activos, reflexivos y críticos tanto respecto de sí mismos como del entorno en el cual se desenvuelven. Algunas de las preguntas orientadoras en cada uno de los niveles son las siguientes:

(1) Autocomprensión

- ¿Cuál es el origen y el sentido del fenómeno moral?

— ¿Qué es la moral?

— ¿Cuáles son sus rasgos más específicos?

(2) Fundamentación

- ¿Por qué comportarnos moralmente? moral?

- ¿Qué razones apoyan el comportamiento

(3) Aplicación

- ¿Cómo actuar moralmente en nuestro ámbito de acción propio?

- ¿Cómo aplicar las respuestas y los argumentos de los dos niveles previos a la esfera de la acción?

- ¿Cómo arribar a una moral crítica, racionalmente fundamentada, en vez de adherir a códigos morales dogmáticamente impuestos?

Ahora bien, ante la imposibilidad de extendernos en detalle en el contenido de cada uno de los niveles y rasgos para las personas que ha dibujado Siurana, se recomienda una lectura directa de su trabajo (véanse las referencias bibliográficas). No obstante, cabe destacar también la vinculación que realiza el autor entre estos planteamientos iniciales y el enfoque de las capacidades de Amartya Sen y de Martha Nussbaum, a partir de lo cual el esquema antes expuesto puede ser releído como lo muestra la Tabla 1.
A partir de esto, tales capacidades «necesitan plasmarse en indicadores concretos en cada uno de los ámbitos de la sociedad en los que actúan los ciudadanos» (Siurana, 2011, p. 34), entre ellos el de Trabajo Social. Mas, como se observa, este segundo esquema sigue siendo un tanto abstracto e impreciso como para que desprendan del mismo directamente unos indicadores para evaluar éticamente a Trabajo Social. Empero, a esta segunda formulación subyace una consideración basal, que puede ser plenamente compartida por dicha profesión, a saber: «se trata de capacidades que los sujetos deben desarrollar, para poder crecer en libertad. Estos rasgos capacitan al sujeto para la participación en los diálogos relevantes donde se tratan cuestiones que les afectan» (Siurana, 2009, p. 330).

El autor propone, con ello, una nueva dirección para su «brújula moral», que intentará servir de guía hacia la concreción de una «sociedad ética», a partir de las tareas de autocomprensión, fundamentación y aplicación, en ámbitos relevantes del despliegue societal como son: la política, la economía, la impartición de justicia, el medioambiente, las empresas, la sanidad, el periodismo, la ingeniería, la informática, las telecomunicaciones, la arquitectura, el arte, el deporte, la investigación y la educación. La idea es reflexionar sobre cómo son de éticas estas áreas en su propio proceso de desarrollo. Junto con esto, se ha definido también un conjunto de respuestas a los desafíos acuciantes para la sociedad mundial actual, derivados de fenómenos y problemáticas tales como: la pobreza, el hambre, el acceso a medicamentos básicos, los conflictos multiculturales, la drogadicción, la violencia de pareja, el terrorismo, la guerra y la transformación genética.

\begin{tabular}{|c|c|}
\hline Niveles y capacidades & Rasgos y capacidades \\
\hline (1) Capacidad para auto-comprenderse & $\begin{array}{l}\text { 1) Capacidad para dotar a la propia actividad de un sentido. } \\
\text { 2) Capacidad para verse desde la perspectiva de los demás. }\end{array}$ \\
\hline $\begin{array}{l}\text { (2) Capacidad para fundamentar sus } \\
\text { juicios en un diálogo con los afectados }\end{array}$ & $\begin{array}{l}\text { 1) Capacidad para la reflexión. } \\
\text { 2) Capacidad para adoptar un criterio intersubjetivo de justicia. }\end{array}$ \\
\hline $\begin{array}{l}\text { (3) Capacidad para llevar a cabo } \\
\text { mancomunadamente los proyectos } \\
\text { de justicia convenidos }\end{array}$ & $\begin{array}{l}\text { 1) Capacidad para asumir una moral postconvencional. } \\
\text { 2) Capacidad para asumir su corresponsabilidad por el resul- } \\
\text { tado de las acciones colectivas. }\end{array}$ \\
\hline
\end{tabular}

Tabla 1.

Fuente: Siruana, 2009, p. 330. 
Como se advierte, el Trabajo Social se relaciona con varios de los ámbitos mencionados, ya sea en tanto que áreas susceptibles de ser evaluadas por medio de indicadores éticos, como respecto de las problemáticas que demandan respuestas para su abordaje. Sin embargo requiere contar con sus propios indicadores.

\subsection{Indicadores éticos para evaluar el Tra- bajo Social}

Cabe precisar que, con anterioridad a la formulación de los indicadores éticos para Trabajo Social, ha sido necesario adecuar las preguntas relativas a los tres niveles antes referidos (autocomprensión fundamentación y aplicación), a fin de iluminar la posterior tarea de elaboración de los indicadores propiamente dichos. En virtud de esto, el esquema reformulado puede expresarse como sigue:

1) Autocomprensión

- ¿Cuál es el impulso ético originario y/o el sentido del Trabajo Social?

- ¿Qué es el Trabajo Social?

- ¿Cuáles son sus rasgos más específicos?

2) Fundamentación

- ¿Por qué conducirnos éticamente en el ejercicio profesional? moral?

- ¿Qué razones apoyan el comportamiento

- ¿Cómo reflejar un criterio intersubjetivo de justicia implícito en el ejercicio profesional?

3) Aplicación

- ¿Cómo actuar éticamente en el ámbito de acción del Trabajo Social?

- ¿Cómo aplicar las respuestas y los argumentos de los dos niveles previos a la esfera de la acción?

- ¿Cómo arribar a una moral crítica, racionalmente fundamentada, en vez de adherir a códigos morales dogmáticamente impuestos?

Cabe precisar además que, siguiendo la estructura diseñada por Siurana, este esquema se divide en dos partes: indicadores para que los propios trabajadores sociales puedan evaluar éticamente su desempeño e indicadores para que los ciudadanos puedan evaluar éticamente al Trabajo Social.

A partir de estas consideraciones, entonces, el esquema de indicadores éticos para Trabajo Social quedaría de la siguiente forma:

\section{La perspectiva de los trabajadores sociales}

\subsection{Nivel de la autocomprensión}

- Entienden su quehacer profesional como indisolublemente ligado a los valores de la igualdad y la justicia, situando a los derechos humanos como horizonte ético-político irrenunciable con miras a la superación de situaciones que menoscaban la dignidad humana.

- Reflexionan sobre la relación entre profesionales y usuarios a fin de desplegar una actitud empática, abierta a la diversidad y dialogante, capaz de reconocer a aquéllos como interlocutores válidos.

\subsection{Nivel de la fundamentación}

- Reflexionan críticamente sobre la dimensión y contenidos deontológicos de su profesión, así como sobre su aplicación frente a la complejidad de las diferentes realidades sociales

- Despliegan su ejercicio profesional, tomando en cuenta la perspectiva de los afectados, pero manteniendo la independencia frente a influencias y presiones tanto institucionales como de parte de los propios usuarios de los servicios, realizando un tratamiento igual de los casos iguales, sin favoritismos ni prácticas clientelares.

\subsection{Nivel de la aplicación}

- Desarrollan procesos de intervención guiados por un criterio de excelencia en el ejercicio profesional, alejados de la burocracia institucional o legal, comprometidos con el pleno desarrollo de las capacidades humanas y respetando de manera irrestricta la confidencialidad que requiere el tratamiento de ciertas situaciones.

- Se involucran en tareas de investigación y de sistematización en equipo, con miras a la producción de conocimientos que mejoren las prácticas de intervención, relevando y rescatando la voz de los sujetos involucrados en dichas prácticas y el potencial transformador encarnado en aquéllas.

\section{La perspectiva de los ciudadanos}

\subsection{Nivel de la autocomprensión}

- Comprenden su condición de sujetos de derechos e interlocutores válidos en procesos dialógicos, con miras a la solución de los problemas que les aquejan. 
- Entienden la relevancia de su participación como afectados en la identificación de problemáticas sociales, en la elaboración de propuestas de abordaje y en la evaluación de los procesos de intervención en que se involucran, teniendo en cuenta las distintas perspectivas implicadas.

\subsection{Nivel de la fundamentación}

- Deliberan en procesos dialógicos acerca de las problemáticas que les afectan, dando a conocer sus puntos de vista a los equipos profesionales.

- Cooperan en el desarrollo de procesos administrativos que les permitan hacer un mejor uso de los servicios y de sus prestaciones, con miras a una optimización y justa distribución de éstos.

\subsection{Nivel de la aplicación}

- Asumen compromisos y participan activamente en iniciativas dirigidas al mejoramiento de las condiciones de vida de sus comunidades, en el marco de procesos de intervención profesional orientados a ello.

- Trabajan por la construcción de un tejido social autónomo capaz de rescatar las especificidades y la riqueza de sus comunidades con miras al abordaje de las problemáticas existentes, generando procesos participativos signados por la inclusión y la corresponsabilidad.

\section{Principales ideas-fuerza del esquema de indicadores éticos para Trabajo Social}

Como corolario, en este apartado se presenta un conjunto de reflexiones vinculadas con ciertos énfasis subyacentes al esquema de indicadores éticos propuesto.

5.1. En primer término, se estima que una de las mayores fortalezas del esquema presentado radica en la incorporación de la perspectiva de los ciudadanos como elemento consustancial al ejercicio de evaluación ética que se pueda desplegar desde el Trabajo Social. Esto resulta altamente valioso porque sitúa a los ciudadanos como sujetos activos en los procesos de intervención social, como voces necesarias de ser consideradas, en oposición a extremos como la hegemonía de los profesionales o el paternalismo de los expertos ${ }^{5}$. Se visualiza a este respecto una condición que Trabajo Social comparte con algunas otras profesiones: el ser «educadoras» o «posibilitadoras» de ciudadanía para otras personas, de forma que «[e]l profesional, realizando su actividad (y por tanto su ciudadanía), posibilita el ejercicio de la ciudadanía de otros miembros de su sociedad.» (Bilbao, 2011, p. 292). Luego, la búsqueda de puntos de encuentro entre ambas perspectivas será nutritiva para la reflexión ética profesional en su conjunto.

Lo anterior se encuentre además en sintonía con los derechos a la autodeterminación y a la participación de los que se habla en la declaración sobre principios éticos de la profesión según la Federación Internacional de Trabajadores Sociales (FITS), en donde se precisa que éstos «deben respetar y promover el derecho de las personas a elegir por sí mismos y a tomar sus propias decisiones» (FITS, 2004).

Asimismo, la inclusión del prisma de los ciudadanos puede ser leída en tres sentidos particulares, mutuamente imbricados:

i) En cuanto los ciudadanos evalúan el desempeño ético de los trabajadores sociales.

ii) En cuanto los trabajadores sociales evalúan éticamente el despliegue de los ciudadanos en relación con los procesos de intervención desarrollados.

iii) En cuanto los trabajadores sociales pueden desprender de dicha evaluación pautas para su propio desempeño profesional, en términos de poder verificar si se cumplen condiciones tales como la autonomía de los sujetos o su derecho a una participación activa y propositiva, entre otros ${ }^{6}$.

5.2. Habida cuenta de las dificultades para aproximar las dimensiones teleológica y prag-

\footnotetext{
${ }^{5}$ Como acertadamente se reconoce a este respecto, «[c]uando se deja todo en sus manos [de los expertos], es fácil que caigan en el secuestro corporativo de los asuntos, en la ideología del profesionalismo. Las operaciones serán técnicamente perfectas, aún cuando los enfermos se mueran.» (Hortal, 1993, p. 72). La analogía con la intervención en Trabajo Social puede ser fácilmente extraíble.

${ }^{6}$ Extensivo a estos tres puntos es lo que señala la FITS en cuanto a que «[1] os trabajadores sociales tienen que asumir la responsabilidad de sus acciones ante los usuarios de los servicios, las personas con las que trabajan» (FITS, 2004).
} 
mática en el ejercicio profesional, se estima que este modelo de indicadores contribuye a la superación de tal distancia. Básicamente:

- Porque puede leerse como una traducción u operativización de las dimensiones teleológica y deontológica, en virtud de lo cual la dimensión pragmática pueda abordarse más fácilmente, pero no por la mera experiencia o el sentido común, sino porque se requiere «proporcionarles recursos y herramientas concretas que puedan solucionar conflictos y dilemas éticos» (Rodríguez, 2014, p. 59).

- Porque el mismo ejercicio evaluativo brinda una perspectiva más nítida respecto de los rendimientos de un determinado quehacer, en este caso, del despliegue ético de los trabajadores sociales.

- Porque la evaluación por medio de indicadores éticos puede contribuir tanto a acercar los planos descriptivo y normativo como a abordar la tensión inherente en ellos, puesto que el proceder evaluativo adopta la forma de una $\mathrm{ra}$ diografia que entrega una imagen para su análisis, a partir de la cual los trabajadores sociales «no sólo han de preguntarse por lo que han sido o lo que pretenden ser sino también cómo son vistos desde fuera y qué es lo que la sociedad espera de ellos.» (Bermejo, 1996, p. 38).

5.3. En tercer lugar, es posible advertir en el esquema de indicadores propuesto una comprensión ética subyacente ligada a valores universales tales como: la dignidad, la justicia o la igualdad, pero no desconectados de los marcos de despliegue profesional. Esto significa que no por tratarse de una tarea evaluativa tenga que responder a criterios utilitaristas, por ejemplo de coste-beneficio o de eficiencia-eficacia en cuanto a lograr el máximo bienestar del mayor número de personas. Este tipo de cánones se encuentra afectado por una "progresiva descontextualización», justamente por la primacía de una mirada utilitarista que se centra en el cálculo de las consecuencias, en cuyo caso «[e]l contexto sólo cuenta en función de ese resultado [...] La falta de contexto hace que la ética pierda realidad y deje de estar en condiciones de hacer propuestas viables de humanización de la vida de los hombres.» (Hortal, 1993, p. 55). Más aún, el campo de lo ético aflora ya no como ese lejano y complejo terreno de los filósofos, ni como el campo de lo emotivo o irracional, sino como ese espacio pleno de sentido y significado, abierto siempre al diálogo racional como condición de posibilidad.

Para Trabajo Social esta adscripción a valores universales como los mencionados es irrenunciable y forma parte de su riqueza. Mas no por remitir a conceptos socialmente valorados o legitimados puede quedar exenta de la necesidad de escrutinio público, es decir, de análisis y diálogo racional. Esta propuesta de indicadores éticos pretende contribuir a evaluar sí y cómo tales valores están cobrando vida en el ejercicio profesional.

5.4. Otro elemento a destacar de la propuesta de indicadores es su acento en la idea de excelencia profesional, pero no sólo como reflejo de un hacer formalmente correcto en sus contenidos o en lo metodológico, sino que respecto de una comprensión de la excelencia como criterio ético rector. Trabajo Social debe estar siempre orientado hacia un desempeño profesional óptimo, de calidad; no puede conformarse con el mero cumplimiento de procedimientos, sino que debe aspirar al más alto grado de excelencia si está realmente comprometido con la transformación de las situaciones que atropellan la dignidad humana.

En efecto, la apelación a la dignidad humana se ubica entre aquellas ideas-fuerza o motores de la acción profesional; bien puede decirse que forma parte del télos del Trabajo Social dada su trascendencia. En consecuencia,

[L]os profesionales del mundo social estamos llamados a la «excelencia» y nuestro compromiso fundamental no es el que nos liga a la burocracia, a los medios, a las estadísticas e instrumentos, sino a las personas reales, concretas, con rostro, cuya dignidad es la que otorga sentido a la actividad profesional (Aguayo, 2006, p. 160).

También, vinculado al tema de la excelencia, es posible destacar del esquema propuesto la relevancia que se otorga a los procesos de investigación y de sistematización como caminos de un despliegue profesional de calidad. En Trabajo Social remite a las posibilidades de acceso $a$, $\mathrm{y}$ de producción $d e$, conocimientos que permitan fortalecer los procesos de intervención transformadores, tender a su mejoramiento y al logro de sus objetivos. Se trata, además, no sólo de las posibilidades de adquirir conocimiento, 
en forma de integración de saberes propios de otras disciplinas, sino también de generar un acervo de aquél en el propio seno profesional. Hay, en definitiva, un impulso ético subyacente al desarrollo epistemológico como criterio de excelencia.

5.5. Como se advierte, otra de las ideasfuerza del esquema de indicadores éticos dice relación con la noción de lo público ${ }^{7}$, en virtud de consideraciones tales como:

a) La ética en sí misma se despliega siempre hacia lo público, porque implica una reflexión sobre valores, principios y normas que se muestran ya siempre encarnados en prácticas específicas, sea a nivel personal, grupal, comunitario o institucional. Las nociones de «lo público» y «lo ético», por tanto, se encuentran íntimamente ligadas.

b) Las profesiones, por su parte, comparten también esta orientación hacia lo público como uno de sus rasgos más característicos, no sólo en términos de la visibilidad (pública) de su ejercicio, sino también en cuanto a su ligazón con una orientación ética que le mueve originariamente.

c) La acción específica de evaluar éticamente es una actividad pública porque implica un dar cuenta, un responder ante otros por el ejercicio profesional, en este caso, de los trabajadores sociales. Y dicho ejercicio se desarrolla ya siempre en un espacio compartido que trasciende a la esfera íntima, aunque se vincule con ésta.

d) Se trata de una manifestación pública con mayor razón aún si en ese evaluar éticamente un ejercicio profesional se incorpora la perspectiva de los ciudadanos, dado que la noción misma de ciudadanía remite al despliegue público de los seres humanos en la sociedad, en oposición a su consideración como individuos particulares. Abrir un espacio a la mirada escrutadora de la ciudadanía supone para el Trabajo Social volcarse hacia lo público. En este sentido, «el ejercicio de la profesión [...] es fuente de ciudadanía, posibilidad concreta y efectiva de realización de la participación activa y responsable en la sociedad, del desarrollo de los derechos y obligaciones inherentes a la condición de miembro de la organización social» (Bilbao, 2011, p. 285).

5.6. Como se aludió al inicio de este artículo, es manifiesta la presencia de un enfoque de derechos humanos inherente al quehacer del Trabajo Social en general, y a este entramado de indicadores éticos presentado en particular. Esto, al menos en tres sentidos:

i. En la consideración primordial de los ciudadanos como sujetos de derechos, partícipes activos de los procesos de intervención, en contraposición con visiones paternalistas que merman su autonomía.

ii. En la adhesión a valores propios de este enfoque, como son la dignidad, la igualdad o la justicia, aspiraciones universalmente reconocidas que el Trabajo Social hace suyas.

iii. En relación con la integralidad de las generaciones de derechos humanos, dado que el Trabajo Social no sólo se encuentra comprometido con demandas relativas a derechos económicos, sociales y culturales (segunda generación), sino también con prerrogativas tendientes a cautelar la autonomía y la libertad de los sujetos y sus posibilidades de participación en tanto ciudadanos (primera generación), como igualmente con derechos colectivos o de solidaridad como son el desarrollo, la paz o un medioambiente libre de contaminación (tercera generación).

5.7. Finalmente, cabe señalar que este esquema de indicadores para evaluar éticamente el Trabajo Social se ubica a sí mismo como una

\footnotetext{
${ }^{7}$ Ciertamente, una noción como ésta ha tenido un amplio desarrollo en áreas como las ciencias sociales o las humanidades. Para la tradición dialógica se trata de un concepto vital en tanto campo en el cual se despliegan los procesos discursivos o deliberativos; no hay posibilidad de diálogo racional sin un contexto público que lo sustente, de forma que — como bien lo sostiene Habermas (2006) - esfera pública, discurso y razón están mutuamente imbricados. Asimismo, la referencia a lo público no debe entenderse como mera oposición a lo privado, sino como un concepto genérico que encierra múltiples diferenciaciones (espacio público-político, espacio público físico, espacio social, espacio público institucionalizado, etc.), las que pueden ser no obstante aglutinadas por una idea común: «ser todos ellos espacios que, con mayor o menor intensidad y connaturalidad, de modo más pleno y directo o de forma más parcial, pueden ser relacionados expresamente con la asunción de responsabilidades por la «cosa pública», con la búsqueda del interés general» (Exteberría, 2011, p. 15).
} 
propuesta abierta al diálogo, a la crítica constructiva y fecunda y, en tal sentido, a su mejoramiento y enriquecimiento. Por lo demás, al ser el ejercicio profesional un devenir, una propuesta como la presentada deberá ser susceptible de actualización permanente con miras a su pertinencia y aplicabilidad.

Justamente en términos de sus posibilidades de aplicación es cuando pueden surgir numerosas inquietudes. Se trata de un esquema nuevo que sólo con el paso del tiempo y su confrontación fáctica podrá ser retroalimentado, modificado y mejorado. Por el momento, basten algunas reflexiones sobre su aplicabilidad, a partir de la consideración de ciertos prejuicios o aprensiones que pueda despertar:

i) Incorporar la perspectiva de los ciudadanos es complicado en términos prácticos: No necesariamente si ello se organiza adecuadamente. $\mathrm{Si}$ bien no en el terreno evaluativo específicamente, existen experiencias sobre integración de la mirada de los usuarios de los servicios sociales, por ejemplo, en el proceso formativo de futuros trabajadores sociales, como muestran por medio de tres experiencias Martínez-Román, Dómenech-López y Tortosa-Martínez (2014, p. 91), quienes enfatizan que «las personas usuarias [...] tienen una gran experiencia personal que les capacita para colaborar como expertos en la gestión de los servicios sociales»».

ii) Ya se cuenta con evaluaciones de desempeño intrainstitucionales, por lo que otro instrumento sería redundante: En la mayor parte de los casos, los sistemas de evaluación del desempeño profesional al interior de las instituciones están centrados en aspectos de rendimiento y actitudinales, pero no específicamente en su dimensión ética. Por la enorme relevancia de ésta, se estima necesario aportar a la construcción e implementación de nuevos instrumentos para evaluar éticamente el desempeño de los trabajadores sociales.

iii) Incluir la percepción de los usuarios es algo que ya se hace por medio de los estudios de satisfacción usuaria: Pero generalmente se trata de instrumentos cuantitativos (tipo encuestas) que no permiten apreciaciones cualitativas sobre el desempeño de los profesionales de los servicios, ni menos sobre el papel de los ciudadanos.

iv) Incluir la participación de los ciudadanos en la evaluación del ejercicio profesional resulta un tanto intimidante: Puede serlo, pero es imprescindible conocer la visión de los usuarios de los servicios al respecto, pues no basta con la propia percepción de que se realiza un trabajo éticamente correcto. Esto es especialmente relevante en el caso de servicios públicos, pues quienes allí se desempeñan son la cara visible del Estado para los ciudadanos que acuden a aquéllos.

v) La conducta éticamente correcta es algo que no se puede medir: No obstante ser la ética un campo de reflexión filosófica originariamente, no resulta imposible su vinculación con distintos ámbitos de la vida humana, entre ellos el de las profesiones; el desarrollo de las éticas aplicadas así lo evidencia. El desglose de indicadores $u$ otros instrumentos similares contribuye a concretar los esfuerzos por evaluar el desempeño ético de los profesionales, como también a acrecentar el acervo ético del Trabajo Social, especialmente frente a constataciones como las que arrojó un estudio sobre la ética profesional realizado entre trabajadores sociales de Valencia, quienes reconocen que «no disponemos de suficientes conocimientos éticos de nuestra profesión» (Manuel, Ortíz y Rueda, 2007, p. 120).

\section{Referencias bibliográficas}

Aguayo, C. (2006). Las profesiones modernas. Dilemas del conocimiento y del poder. Santiago de Chile: Universidad Tecnológica Metropolitana.

Apel, K.-O. (1985). La transformación de la filosofia. Madrid: Taurus.

Bermejo, F. (1996). La ética profesional en el Trabajo Social. En F. Bermejo (coord.), Ética y Trabajo Social (pp. 15-45). Madrid: Universidad Pontificia Comillas.

Bilbao, X. (2011). Profesional responsable y ciudadano comprometido. En A. Hortal y X. Exteberría (eds.), Profesionales y vida pública (pp. 15-35). Bilbao: Desclée de Brower.

Federación Internacional de Trabajadores Sociales. (FITS) (2004). Ética en el Trabajo Social. Declaración de principios. Adelaida: Autor.

Habermas, J. (2006). Espacio público y esfera pública política. Raíces biográficas de dos motivos intelectuales. En J. Habermas, Entre naturalismo y religión (pp. 19-30). Barcelona: Paidós. 
Hortal, A. (1993). Planteamiento de una ética profesional. En J. L. Fernández y A. Hortal (comps.), Ética de las profesiones (pp. 55- 73). Madrid: Universidad Pontificia Comillas.

Manuel, J. A., Ortíz, E. y Rueda, P. (2007). Aproximaciones al estudio de las prácticas profesionales de los trabajadores sociales en ejercicio. El caso de Valencia. En C. Aguayo, T. López y T. Quiroz. Ética y Trabajo Social en las voces de sus autores: un estudio desde la práctica profesional (pp. 91-125). Santiago de Chile: Colegio de Asistentes Sociales de Chile.

Martínez-Román, M.A., Domenech-López, Y. y Tortosa-Martínez, J. (2014). Aprender conociendo a las personas usuarias de los servicios. Azarbe, 3, 93-98.

Morales, P. (2010). Servicio Social en Chile en los años '20 y '30: el cuidado del otro como una cuestión de mujeres. En M. González (ed.), Historias del Trabajo Social en Chile, 1925-2008. Contribución para nuevos relatos (pp. 32-48). Santiago de Chile: Ediciones Técnicas de Educación Superior.

Rodríguez, C. (2014). Ética y Trabajo Social: La reflexión de la profesión, camino de ciudadanía. Azarbe, 3, 55- 61.

Rosell, T. (2000). El futuro del Trabajo Social: oportunidades y retos. En Pasado, presente y futuro del Trabajo Social. Actas del II Foro de Trabajo Social (pp. 99-107). Madrid: Universidad Pontifica de Comillas.

Siurana, J. C. (2009). La sociedad ética. Indicadores para evaluar éticamente una sociedad. España: Proteus.

Siurana, J. C. (2011). Las capacidades ético-discursivas como capacidades para el reconocimiento recíproco: bases de un modelo de desarrollo humano. Éthique et économique/Ethics and Economics, 8, 25-39. 